\title{
Assessing relationship between lip prints, finger prints and different blood groups within the population of Karachi
}

BEENISH FATIMA ALAM ${ }^{1}$, MADIHA ANWAR ${ }^{2}$, KAWISH SYED $^{3}$, TABASSUM AHSAN $^{4}$, SIKANDAR JAVED BAJWA ${ }^{5}$, TALIB HUSSAIN ${ }^{6}$ SAQIB ALI ${ }^{7}$

${ }^{1}$ Assistant Professor of Oral Biology, Bahria University Medical and Dental College, Karachi, Pakistan

${ }^{2}$ Department of Oral Biology, Bahria University Medical and Dental College, Karachi, Pakistan

${ }^{3}$ Department of Periodontology, Sardar Begum Dental College, Gandhara University, Peshawar, Pakistan

${ }^{4}$ Department of Orthodontics, Bahria University Medical and Dental College, Karachi, Pakistan

${ }^{5}$ Associate Professor of Oral Biology, Lahore Medical \& Dental college, Lahore, Pakistan

${ }^{6}$ Professor Department of Oral Biology, Women Medical \& Dental College Abbottabad

${ }^{7}$ Department of Biomedical Dental Sciences, College of Dentistry, Imam Abdulrahman Bin Faisal University, Dammam, Saudi Arabia

Correspondence to Dr Sikandar Javed Bajwa Email sikandar.bajwa15@gmail.com

\begin{abstract}
Aim: To determine the correlation between lip print, fingerprint form and blood groups that can be used for the identification of an individual among gender.

Method: This cross-sectional study was conducted among 719 female and male participants with ages between 17-34 years from Bahria University Medical and Dental College. Patterns for lip and finger prints were collected along with the blood groups. SPSS v23 was used for statistical analysis. Frequency and percentages of the qualitative variables was calculated. The association of the variables was analyzed using Chi-square.

Results: A total of 719 subjects, there were 327 males (45.5\%) and 392 females (54.5\%). Type I lip pattern was prevalent in $31.8 \%$ males followed by Type I' in $27.6 \%$ females. The loop type of the finger print was observed in $165(50.5 \%)$ of males and $162(41.3 \%)$ females. The most common type of blood group was $A+$ in $27.2 \%$ in males while in females it was $0+$ in $29.8 \%$.

Conclusion: Individual parameters such as lip and finger prints along with blood groups can play an important role in personal identification of individual. In our study A+ blood group along with arch pattern of finger prints and Type I lip were most common patterns in males while in females Type l'lip pattern along with blood group 0+ and Loop pattern were common

Keywords: Lip prints, Finger Prints, Cheiloscopy, Blood Groups, Forensic
\end{abstract}

\section{INTRODUCTION}

Every single individual has well defined features that make them completely different from others. ${ }^{1}$ Identification of an individual is a critical and an exacting job in relation to the forensic investigation. However, fingerprint and DNA examination are most commonly employed methods which are used to assure secured and quick identification, whereas in some cases other methods are used that comprises of lip printing, hand writing, bite marks, rugae pattern on the palatal surface, anthropometry, determination of sex and age, measurement of weight and height, blood group identification and post-mortem reports for identification..$^{2-4}$ Lip prints and finger prints plays an important role in the identification of a person, since DNA investigation are not commonly available in underdeveloped countries. The current research was conducted on undergraduate students and faculty in a dental college and can provide an inexpensive and easy human identification method ${ }^{5}$.

As the finger prints are commonly used worldwide for personal identification. ${ }^{6}$ The wrinkles on the skin of plantar and palmar surface, with tiny narrow ridges are called friction ridges and the impression of these friction ridges is referred as fingerprint $^{7-9}$. Dermatoglyphics is the name given to the study of the patterns of the finger prints ${ }^{10}$. Moreover these patterns of the fingerprint are coded on the surface of the dermis in such manner that even in cases of injury to the skin these pattern are not destroyed ${ }^{11}$. Henry's classification is one of the most commonly used system that allows classification of fingerprint into three basic patterns which includes Arch type, Loop type and Whorl pattern. ${ }^{12}$ Studies have shown that fingerprints are a reliable method for personal identification and are widely used in biometric identification throughout the world ${ }^{13-15}$.

Similar to finger print, lip print has also been accepted and trusted as standard for individual identification ${ }^{6}$. Lip prints are formed by a special pattern known as Sulci laborium which are the basically the grooves and wrinkles present on the labial mucosa and the study of the lip prints is named as the cheiloscopy ${ }^{16}$. Lip prints are further classified into six classes by Yasuo tsuchichashi, according to the form, shape and the grooves pathways ${ }^{17,18}$. Like

Received on 11-05-2021

Accepted on 21-09-2021 fingerprints, lip prints also provide an effective source of identification. A study conducted on identical twins reported that the twins who were unable to be differentiated by any other means were identified using lip prints, therefore, can be used as a means of identification of an individual. ${ }^{3,19}$ The lip prints present on a surface can remain viable for up to 30 days. Several methods have been introduced to lift invisible lip prints such as use of aluminum powder, silver nitrate powder, indigo dyes and others.

Karl Landsteiner in 1901 identified the different blood group system $^{20}$. This blood group system can be further categorized as $A$, $\mathrm{B}, \mathrm{AB}, \mathrm{O}$ blood group according to the corresponding antigen that is present, while the Rhesus system is classified into $R h+$ and $R h-$ conferring to the presence or absence of $D$ antigen ${ }^{21}$.

Studies correlating and assessing relation among blood group lip and finger prints are quite few. However, some studies have demonstrated significant association between the three variables $^{10,11,22}$. To the best of our knowledge Pakistan has no published study so far that has focused on assessing the relation between these three variables. Study conducted by Gardezi $S$ et al, focused only on lip print for the identification of gender while no other variable was considered. ${ }^{23}$ In the study conducted by Nandan et al. significant association was demonstrated between lip prints and finger prints and they can be used for gender identification ${ }^{24}$.

The aim of this study was to determine the association between lip print pattern, fingerprint pattern and blood group, which can provide substantial data for the forensic identification.

\section{MATERIALS AND METHODS}

This cross-sectional study was conducted primarily among the female and male faculty members and students of BUMDC. Informed consent was taken from all participants before taking the impressions. Responses were kept anonymous to maintain the confidentiality of the participants. Inclusion criteria for the study included healthy participants having no systemic, metabolic, dermatological or endocrinal disease. While participants presenting with any bacterial, viral or fungal infections affecting lips and hands, or having worn fingerprints, extra, webbed or bandaged fingers, and those having permanent scars on fingers or lips caused by injuries, inflammation or surgery were excluded. 
Method of collection of fingerprints: For the impression for finger, right thumb of participants was taken into account as this is the commonly used legally. The fingerprint patterns were analyzed following the Michael Kucken's finger print classification ${ }^{25}$.

- Arch

- Loop

- Whorl

- Composite containing two or more forms

Method of collection of lip prints: The participants were asked to clean their lip and to dry for 1 minute and then a red lipstick was applied uniformly over the lips. The strip of cellophane was removed and placed over the white bond paper (A4) without any wrinkles for a stable record. The lip prints were further analyzed using the classification by Suzuki and Tsuchihashi that was done using a magnifying glass ${ }^{26}$

\section{Classification of lip prints by Suzuki and Tsuchihashi}

Type I Vertical grooves

Type I' Partial length across the lip grooves of type I

Type II Branched grooves

Type III Intersecting grooves

Type IV Reticular grooves

Type V Other pattern

Method of determining $\mathrm{ABO}$ blood group: The blood grouping was done by collecting blood from the participants. The finger of the participants was pricked and a drop of blood was placed on a glass slide. The blood drop was then treated with anti-A, anti-B and then anti-Rh sera. The blood group was labeled as $A$ upon positive agglutination of the blood upon treatment with anti-A sera. The blood group was labeled as $B$ upon a positive reaction with anti-B serum. If no agglutination was produced it was blood group $\mathrm{O}$. The agglutination of blood with both antisera, the blood group was identified as $A B$. A positive agglutination reaction with $R h$ antigen was considered as $\mathrm{Rh}+$, or $\mathrm{Rh}-$

Statistical analysis: The results were tabulated and analyzed using SPSS version 23 (Microsoft Corporation Inc., Chicago, IL, USA) statistical software, as it is a powerful tool specially designed for performing simple and complex statistical analysis. Statistical conditions used were $95 \%$ confidence interval with $5 \%$ margin of error. The required sample size was found to be 719 . Keeping the margin of $5 \%$ attrition we increased the sample size to 719 participants. Sample size was calculated using OpenEpi 3. All the qualitative variables are presented as frequency and percentages. Chi-square was applied to see the association between the qualitative variables. $P$-value $<0.05$ considered to be significant.

\section{RESULTS}

The data was collected from a total of 719 subjects, aged between 18 to 35 years. There were males $327((45.5 \%)$ and 392 females $(54.5 \%)$. It can be observed from table 1 that type I lip pattern is prevalent in $104(31.8 \%)$ males) followed by type I' in $73(22.3 \%)$ males. Type I' was observed in 108(27.6\%) females followed by Type I in 102(26\%) females. The Type IV lip pattern was the least common type observed in both the genders. No statistically significant difference was observed in lip patterns of males and females $(p$-value $=0.15)$

Table 2 shows the prevalence of different finger print patterns in both genders. The loop type of the finger print was observed in 165(50.5\%) of males and 162(41.3\%) females followed by arch type in $165(35.5 \%)$ of males and $141(36 \%)$ in females. It was observed that the finger print patterns had significant difference between males and females ( $p$-value $=0.006$ ).

Table 3 shows the distribution of different blood group types in males and females. The most common type of blood group was $\mathrm{A}+$ in $89(27.2 \%)$ males followed by $\mathrm{O}+$ in $83(25.4 \%)$ males. The most common type of blood group in females was $\mathrm{O}_{+}$in $117(29.8 \%)$ followed by B+ in $109(27.8 \%)$. Among the Rh- type, Btype was observed in the both the genders while $A$ - was only seen in males. AB- and O- blood type was not observed in our study. The blood group types were statistically significant between males and females ( $p$-value $=0.029)$

In table 4 it can be seen that Type I and Type I' are the most frequently observed lip print types. Type $I$ is most frequently associated with $B+(33 \%), A B+(43.5 \%)$ and $B-(43.1 \%)$. While type l' is frequent with $A+(32.3 \%)$ and $O+(25 \%)$. Interestingly, the individuals with $\mathrm{O}+$ blood group have almost equal distribution of Type I' (25\%), Type II (24\%) and Type IV (23.5\%) lip patterns. Type II and type III lip patterns were absent in B- blood group. The $\mathrm{p}$-value was highly significant indicating that blood groups are strongly associated with lip print patterns ( $p$-value $<0.001)$.

It can be seen in the table 5 that persons with $A+$ and $B-$ blood group, most frequently have arch type of finger prints $(53.1 \%$ and $62.7 \%$ respectively). The loop type of finger print is frequently associated with all the other blood group types, i.e. $B+(52 \%), A B+$ $(66.3 \%), O+(46.5 \%)$ and A- $(100 \%)$. The p-value is statistically significant indicating that blood group type and finger print classification is significantly associated ( $p$-value $<0.001$ ).

The Chi-square statistic shows that lip prints and finger prints have statistically significant association between them ( $p$ value $<0.001$ ). The loop type of finger print was the most frequent type in all the lip print patterns except Type IV type of lip prints. The type IV type had arch type of finger prints (54.1\%) as most common type. The Type III type of lip prints has equal distribution of arch and loop type of finger prints (34.3\% each).

\section{DISCUSSION}

The current study was conducted to assess the correlation of lip prints, finger prints and blood groups among males and females. Lip prints are unique to everyone and they can provide a link to the identity of a person. The lip prints are normal lines and fissures found on the vermilion border of upper and lower lip. ${ }^{27}$ The lip prints are classified into six types on the basis of grooves and fissures ${ }^{28}$. They can be developed and visualized in a pattern similar to vermillion borders. The lips have the tendency to recover easily after minor trauma and inflammation and they remain the same throughout life. It has been reported that lip prints can be obtained from the crime scenes up to 30 days after being produced. ${ }^{29}$ One of the drawback observed in the current study while taking lip prints was that the participants tend to create pressure towards the center of the vermillion border. This may result in the distortion of the lip print and even create difficulty in analyzing the pattern. To overcome this issue the lip prints were taken thrice from the same person and the prints which produced the best result were used for the final analysis. In this study, it was observed that lip prints of every individual were different from the other person, thus confirming the uniqueness of the lip prints, which is in accordance to many other studies ${ }^{3,30,31}$.

In this study the most common lip print pattern in males was type $\mathrm{I}(31.8 \%)$, which is a clear-cut groove running vertically across the lip while in females Type I' $(27.6 \%)$ was the most common type. The study conducted on residents of Mangalore observed type $\mathrm{I}^{\prime}$ as the common type in males and females ${ }^{28}$.

Similarly finger prints are also unique to every individual and are now regularly being used for biometric analysis due to their uniqueness. The fingerprints are formed during 12-19 weeks of the intra uterine life and they remain the same throughout the life. They have provided strong evidences of personal identification during crime scenes ${ }^{32}$. The uniqueness was confirmed in this study as well, as no similar finger prints between any two individuals were observed. The most frequent type of finger print was loop type within males (50.5\%) and females (41.3\%). The least common type was whorl type in both genders. These findings are in contrast from the study conducted in India where they found arches and whorls pattern to be common in the females. The difference in results could be due to less sample size in their study. Rastogi et al. identified loop pattern as the most common type in females and males $^{33}$.

The most common type of blood group was $A+$ in males $(27.2 \%)$ and $\mathrm{O}_{+}$in females (29.8\%). These findings are in disagreement with a study conducted by Khalid and Qureshi who identified Blood $\mathrm{B}+$ to be most prevalent type in females and $\mathrm{O}+$ in males $^{34}$

In our study significant correlation between blood groups and lip prints and between blood groups and finger prints was observed. In an Indian study no significant correlation between the 
three variables was observed ${ }^{35}$. Research by Mehta et al. also reported presence of association between the finger print pattern and blood groups ${ }^{36}$. Another study that assessed the association of thumb prints and blood groups also reported no significant association between them ${ }^{17}$. In the current study significant correlation between arch, loop and whorl type of the fingerprint was seen with Type I finger prints (P-value $<0.001)$. In study by Negi, A and Negi A. correlation of lip prints with finger prints was studied and they identified loop pattern as the most common type among males and females however no significant correlation was observed between finger and lip prints ${ }^{37}$.

Blood groups in combination with lip prints and finger prints can provide substantial evidence for the identification of a person as blood samples are most commonly left at any crime site after finger prints and lip prints. ${ }^{38}$ There is limited data available for correlating blood groups, finger prints and lip prints. In the current study statistically significant association can be seen in blood group O+ group with Type I' and Type I lip print pattern while the loop type of finger print was the predominant type in $\mathrm{O}+$ blood group type and whorl was the least common. Similarly $A+$ blood group showed positive correlation with Type I and Type I'lip print patterns while the most common finger print pattern was Arch type followed by loop pattern. The current study shows correlation between the three variables which indicates their importance.

Limitations: One of the major limitations of this study was the lack of individuals with Rh- blood group. We tend to address these issues in future by conducting a multi-center study with equal distribution of male and female study participants.

\section{CONCLUSION}

Individual parameters such as lip and finger prints along with blood groups can play an important role in personal identification of individual. In our study $A+$ blood group along with arch pattern of finger prints and Type I lip were most common patterns in males while in females Type I 'lip pattern along with blood group 0+ and Loop pattern were common.

Recommendations: It is recommended to anticipate further studies incorporating a larger sample size which can provide substantial data for the forensic identification of an individual.

Source of Funding: Nil

Conflict of Interest: No conflicts of interest to declare.

Ethical Approval: Formal Approval of the study was attained from the Ethical Review Committee of Bahria University Medical and Dental College before starting the study

\section{REFERENCES}

1. Karim B, Gupta D. Cheiloscopy and blood groups: Aid in forensic identification. The Saudi dental journal. 2014;26(4):176-80.

2. Amith H, Ankola AV, Nagesh L. Lip prints-can it aid in individual identification. J Oral Health Comm Dent. 2011;5(3):113-8.

3. Kumar GS, Vezhavendhan N, Vendhan P. A study of lip prints among Pondicherry population. Journal of forensic dental sciences. 2012;4(2):84.

4. Murugan M, Karikalan T. A study of relative correlation between the pattern of finger prints and lip prints. Journal of evolution of medical and dental sciences. 2014;3(56):12768-73.

5. Eboh DE. Fingerprint patterns in relation to gender and blood group among students of Delta State University, Abraka, Nigeria. Journal of experimental and clinical Anatomy. 2013;12(2):82.

6. Adamu LH, Taura MG, Hamman WO, Ojo SA, Dahiru AU, Sadeeq $\mathrm{AA}$, et al. Association of lip print and sex among Nigerians. Nigerian Journal of Basic and Clinical Sciences. 2012;9(2):79.

7. Patel S, IshPaul M, AS GR, Sowmya G. Research Article A study of lip prints in relation to gender, family and blood group. 2010.

8. Verghese AJ, Mestri SC. A study of efficacy of lip prints as an identification tool among the people of Karnataka in India. Journal of Indian Academy of Forensic Medicine. 2011;33(3):200-2.

9. Verghese AJ, Somasekar M, Umesh Babu R. A study on lip print types among the people of Kerala. Journal of Indian Academy of Forensic Medicine. 2010;32(1):6-7.

10. Srilekha N, Anuradha A, Vijay Srinivas G, Sabitha Devi R. Correlation among lip print pattern, finger print pattern and $A B O$ blood group. Journal of clinical and diagnostic research: JCDR. 2014;8(3):49.
11. Sandhu $H$, Verma $P$, Padda $S$, Sunder Raj $S$. Frequency and correlation of lip prints, fingerprints and $\mathrm{ABO}$ blood groups in population of Sriganganagar District, Rajasthan. Acta medica academica. 2017;46(2).

12. Henry E. Classification and uses of fingerprints London. George Rutledge and Sons, Limited. 1900;54.

13. Rivaldería N, Gutiérrez-Redomero E, Alonso-Rodríguez C, Dipierri JE, Martín LM. Study of fingerprints in Argentina population for application in personal identification. Science \& Justice. 2017;57(3):199-208.

14. Shen W, Tan T. Based on Personal Identification-Automated Biometrics. Sci J Biome and Biost. 2018;1(1):001-2.

15. Bose PK, Kabir MJ. Fingerprint: A unique and reliable method for identification. Journal of Enam Medical College. 2017;7(1):29-34.

16. Bhavana D, Ruchi J, Prakash T, JL K. Study of fingerprint patterns in relationship with blood group and gender-a statistical review. Arches. 2013;1(1):15-7.

17. Adamu L, Taura M, Hamman W, Ojo S, Dahiru A, Sadeeq A, et al. Relationship of thumb prints and lip prints among Nigerians. IOSRJDMS. 2013;9(2):12-7.

18. Nagasupriya A, Dhanapal R, Reena K, Saraswathi T, Ramachandran C. Patterns-"A crime solver". Journal of forensic dental sciences. 2011;3(1):3.

19. Ragab AR, El-Dakroory SAE-A, Rahman RHA. Characteristic patterns of lip prints in Egyptian population sample at Dakahlia Governorate. International journal of legal medicine. 2013;127(2):521-7.

20. Storry J, Olsson ML. The ABO blood group system revisited: a review and update. Immunohematology. 2009:25(2):48.

21. Smail HO, Wahab DA, Abdullah ZY. Relationship between pattern of fingerprints and blood groups.

22. Harsha L. Correlation of lip print, finger print and blood groups in a Tamil Nadu based population. Journal of Pharmaceutical Sciences and Research. 2015;7(9):795

23. Gardezi S, Hassan N, Memon S. Analysis of Lip Print for Gender Identification in Karachi (Pakistan) Population. Journal of Advances in Medicine and Medical Research. 2017:1-6.

24. Nandan SRK, Bandaru BK, Santosh ABR, Thankappan P, Chundru NSV, Amudala R. A study on association and correlation of lip and finger print pattern analysis for gender identification. Journal of $\mathrm{Dr}$ NTR University of Health Sciences. 2015;4(3):176.

25. Kücken M, Newell AC. Fingerprint formation. Journal of theoretical biology. 2005;235(1):71-83.

26. Suzuki K, Tsuchihashi Y. New attempt of personal identification by means of lip print. Journal of the Indian Dental Association. 1970;42(1):8.

27. Saraswathi T, Mishra G, Ranganathan K. Study of lip prints. Journal of forensic dental sciences. 2009;1(1):28.

28. Jeergal PA, Pandit $S$, Desai D, Surekha $R$, Jeergal VA. Morphological patterns of lip prints in Mangaloreans based on Suzuki and Tsuchihashi classification. Journal of oral and maxillofacial pathology: JOMFP. 2016;20(2):320.

29. Reddy LVK. Lip prints: An overview in forensic dentistry. Journal of Advanced Oral Research. 2011;2(1):17-20.

30. Ahmed S, Salem HE, Fawzy MM. Forensic dissection of lip print as an investigative tool in a mixed Egyptian population. Alexandria Journal of Medicine. 2018;54(3):235-9.

31. Alzapur A, Nagothu RS, Nalluri HB. Lip prints-A study of its uniqueness among students of MediCiti Medical College. Indian journal of clinical anatomy and physiology. 2017;4(1):68.

32. Huynh C, Brunelle E, Halámková L, Agudelo J, Halámek J. Forensic identification of gender from fingerprints. Analytical chemistry. 2015;87(22):11531-6.

33. Rastogi P, Pillai KR. A study of fingerprints in relation to gender and blood group. Journal of Indian Academy of Forensic Medicine. 2010;32(1):11-4.

34. Khalid M, Qureshi M. Frequencies of blood group antigens and corresponding alleles in the population of Mirpur, Azad Jammu Kashmir, Pakistan. The Journal of Animal and Planet Sciences. 2006;16(3-4):96-8.

35. Krishnan RP, Thangavelu R, Rathnavelu V, Narasimhan M. Gender determination: Role of lip prints, finger prints and mandibular canine index. Experimental and therapeutic medicine. 2016;11(6):2329-32.

36. Mehta AA, Mehta AA. Palmar dermatoglyphis in ABO, RH Blood groups. Int J Biol Med Res. 2011;2(4):961-4.

37. Negi A, Negi A. The connecting link! Lip prints and fingerprints. Journal of forensic dental sciences. 2016;8(3):177.

38. Srinivasulu K, Katikaneni PS, Abbagoni V. Study on Pattern of Lip Prints and its Relation to Sex and Blood Groups in Telangana Population. Medico Legal Update. 2020;20(4):267-72. 